\title{
sala \\ de

\section{SOMA DE INTEIROS POSITIVOS E NEGATIVOS NOS ANOS INICIAIS: UMA ABORDAGEM POSSÍVEL}

\author{
SUM OF POSITIVE AND NEGATIVE NUMBERS IN THE EARLY YEARS: AN APPROACH POSSIBLE \\ FABIO MENEZES \\ SME-DUQUE DE CAXIAS/RJ E FFP-UERJ \\ professorfabioms@gmail.com
}

MICHELE BARABANI

SME-RIO DE JANEIRO/RJ

barabani.mi@gmail.com

ALINE REGINA

SME-RIO DE JANEIRO/RJ

alinealves81@gmail.com

\begin{abstract}
Resumo: neste relato de pesquisa visamos refletir sobre uma prática investigativa acerca do ensino de números inteiros negativos nos anos iniciais do ensino fundamental, idealizada e realizada por meio de uma parceria entre pares que ensinam matemática em diferentes etapas de escolarização. Em nossa investigação como uma postura docente, produzimos os dados observando o uso de um jogo digital como recurso didático, considerando, para análises, os momentos em que a literatura o reconhece como 'transparente' e se aprende com ele. Questionamos, a partir de contextos históricos, um suposto obstáculo epistemológico, que relega a aprendizagem sobre os números negativos a partir do sétimo ano de escolaridade, mas que nos pareceram facilmente ultrapassados pelas crianças devido à nossa abordagem. Consideramos, ainda, repensar o paradigma curricular em deslocar o ensino dos negativos já para os anos iniciais, entendendo que o ensino da matemática escolar é uma prática socialmente situada.
\end{abstract}

Palavras-chave: Números Negativos. Anos Iniciais. Recurso Didático. Obstáculo Epistemológico.

\begin{abstract}
: in this research report we aim to reflect on an investigative practice about teaching negative integers in the early years of elementary school, idealized and carried out through a partnership between peers who teach mathematics at different stages of schooling. In our investigation as a teaching posture, we produced the data observing the use of a digital game as a didactic resource, considering for analysis, the moments when the literature recognizes it as 'transparent' and learns from it. We question, based on historical contexts, a supposed epistemological obstacle, which relegates learning about negative numbers from the seventh year of schooling, but which seemed to us easily overcome by children due to our approach. We also consider rethinking the curricular pattern in displace the teaching of negatives to the early years, understanding that the teaching of school mathematics is a socially situated practice.
\end{abstract}

Keywords: Negative Numbers. Early Years. Didactic Resource. Epistemological Obstacle.

\section{INTRODUÇÃO}

Relacionar, contar, medir, levantar hipóteses e tirar conclusões são aprendizagens desejáveis em torno do que entendemos ser a ciência dos padrões: as matemáticas. Escolhemos usar o plural para demarcar nosso entendimento de que as maneiras de produzir, ensinar e aprender são situadas em 


\section{sala \\ de $\oplus$ em \\ aula foco}

REVISTA ELETRÔNICA

cada tempo e espaço, como sugere Lave (1991), e a matemática como campo de conhecimento não estaria, assim, fora desta condição.

Nessa perspectiva, no ano letivo de 2018, uma parceria formalmente autorizada entre o Laboratório Sustentável de Matemática (LSM), por meio da pessoa do primeiro autor deste relato - professor de matemática e um dos coordenadores do LSM - e duas professoras de uma escola da rede pública do município do Rio de Janeiro - também autoras deste relato - possibilitou a realização de diversos experimentos de cunho matemático com alunos do 2ㅇano do Ensino Fundamental, atendidos por essas professoras. Inicialmente, essa parceria era baseada em sustentabilidade e meio ambiente, possibilitando realizar ações como:

- coletar o lixo exposto pela escola e pesquisar, na Internet, o tempo de deterioração desse lixo;

- fazer papel reciclado, controlando a proporção;

- plantar e cuidar de um jardim, controlando a quantidade de água e medir a massa de terra retirada de um buraco feito para plantar uma muda; e

- medir e registrar a evolução da altura de uma muda de pau-brasil, plantada na área verde da escola e confeccionando papel reciclado (FIGURA 1).

Figura 1 - Lixo catado e pesquisado, plantação de uma muda e confecção de papel
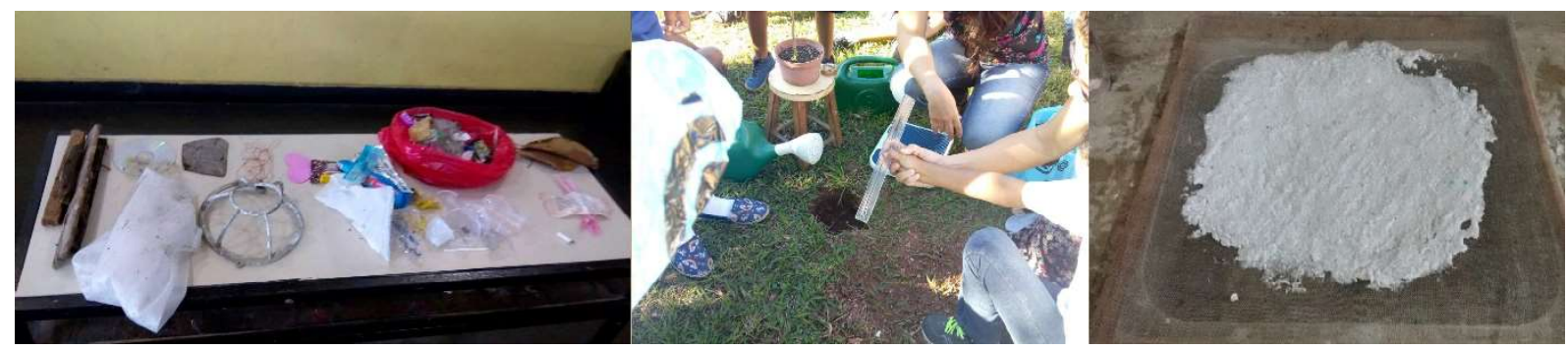

Fonte: nossa, 2018.

Nesse ambiente de experimentação, percebendo que era possível oferecer experiências que desenvolvessem o conhecimento matemático com sentido e significado, situadas em seu tempo e espaço, resolvemos investigar o ensino do conceito de números inteiros positivos e negativos, normalmente oferecido a partir do 70 ano de escolaridade, com estudantes dos anos iniciais. Nossa 


\section{sala \\ de $\theta$ em \\ aula foco}

REVISTA ELETRÔNICA

ISSN 2316-7297

escolha se deveu ao fato de que os estudantes já têm contato diariamente com tais números, seja em notícias sobre temperatura, economia ou até em saldo de gols de um campeonato de futebol, por exemplo. Contudo, para realizar essa investigação, procuramos um outro elemento que também fizesse parte do escopo da paisagem cotidiana dos estudantes: um jogo usando tecnologia digital.

Dessa forma, buscamos nesse trabalho refletir a respeito de uma experiência de ensino da operação de soma com números inteiros nos anos iniciais de escolarização, usando um jogo idealizado por nós, autores, no programa Scratch ${ }^{1}$ (FIGURA 2), entendendo que nossa busca é um posicionamento de investigação sobre a nossa própria prática docente, como propõem Cochran-Smith e Lytle (2009), que professores tenham a investigação como postura profissional, permitindo uma compreensão mais próxima das relações entre conhecimento e prática.

Figura 2 - Telas inicial e do escopo jogo contendo números positivos e negativos que se movem no desert

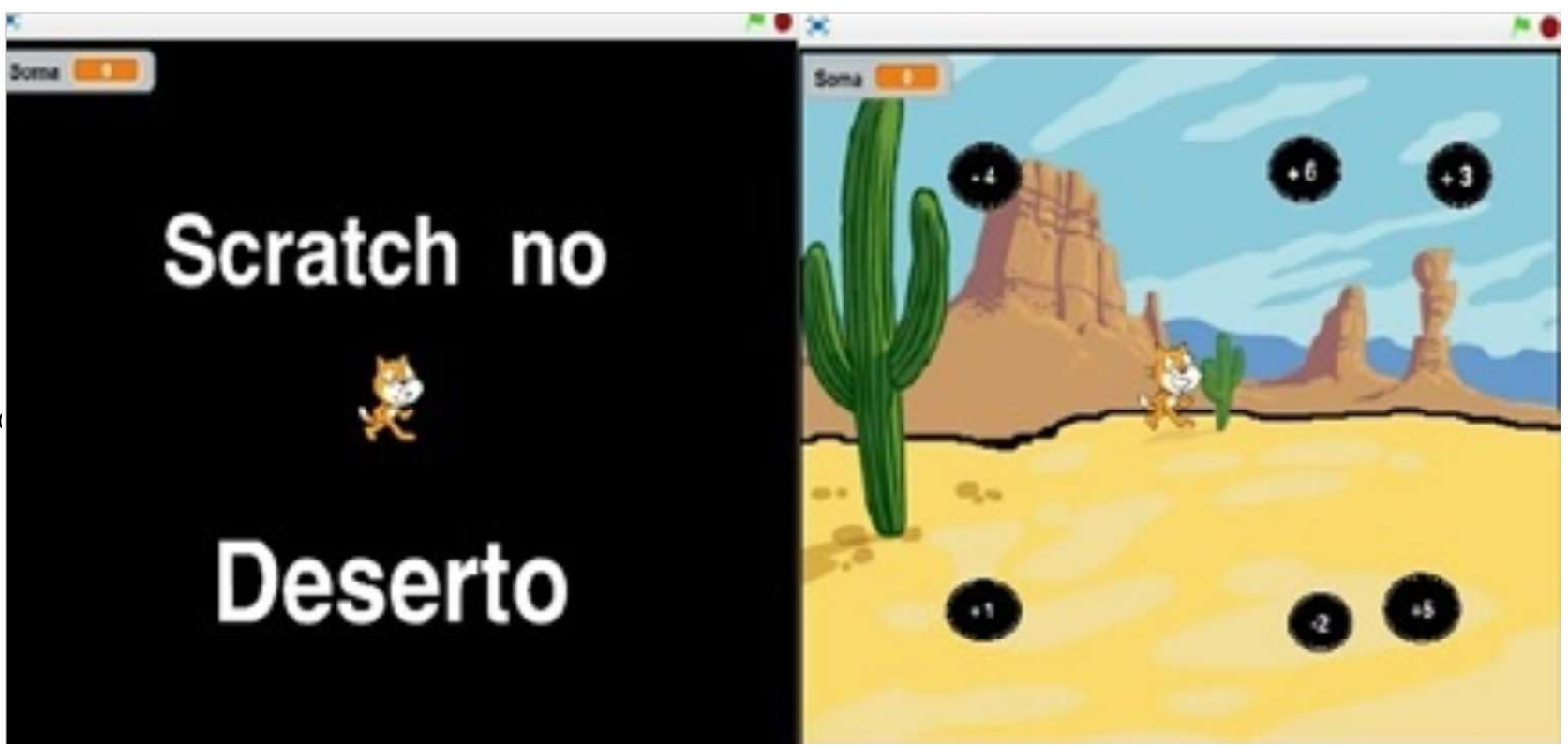

Fonte: nossa, 2018

Na realização dessa investigação, que podemos chamar de experiência piloto sobre o uso de um jogo para promover o ensino-aprendizagem de soma de números inteiros positivos e negativos, oferecemos o jogo a dois estudantes do 20 ano de escolaridade escolhidos ao acaso para que, individualmente, o testassem de maneira preliminar a fim de fazermos ajustes e, assim, oferecermos para uma turma completa.

\footnotetext{
${ }^{1}$ Programa de computador gratuito que possibilita fazer programação através de blocos lógicos de linguagem.
} 


\section{sala \\ de $\oplus$ em \\ aula foco}

-REVISTA ELETRÔNICA

Entretanto, é sobre essa aplicação feita aos dois estudantes que tecemos observações e reflexões que nos pareceram importantes de serem comunicadas, para ajudar a construir respostas a uma questão curricular, a saber: "Como nossas ações docentes podem influenciar numa questão curricular de não ser preciso esperar até o 70 ano de escolaridade para começar a ensinar sobre os números negativos?". Para isso, na próxima seção, fizemos um breve diálogo teórico que constrói uma lente analítica para as nossas observações, depois descreveremos o funcionamento e a aplicação do jogo com nossas análises, trazendo, por fim, nossas considerações acerca desta investigação.

\section{UM BREVE DIÁLOGO TEÓRICO COMO LENTE ANALÍTICA}

Diante de nossas inquietações sobre o ensino dos números negativos, descobrimos que, desde o reconhecimento deles como parte de um conjunto numérico, há estudos que consideram fatos históricos nos quais o examinam e o questionam como um 'obstáculo epistemológico' (SCHUBRING, 2012). Nesses estudos, ora referidos, há uma reflexão histórica sobre o uso dos números negativos dentro da matemática hegemônica, tradicionalmente eurocêntrica, cuja base era a grandeza como meio de medida. Dessa forma, não parecia, realmente, que havia espaço para o desenvolvimento numérico dos negativos, sendo encontrados resultados negativos válidos apenas no século XV, em um tipo de manuscrito provençal, com "uma solução negativa admitida sem restrições:- $10 \frac{3}{4}$ (ver Sesiano 1984)" (SCHUBRING, 2012, p.35).

Essa certa estranheza sobre os números negativos fomentou discussões durante séculos entre diversos renomados matemáticos europeus, até que uma "abordagem definitiva foi estabelecida em 1817 por um professor de matemática de um Gymnasium prussiano, em Danzig: Wilhelm A. Förstemann (1791-1836)" (SCHUBRING, 2012, p.62), mas só foi amplamente divulgada após 1867. Förstemann estabeleceu diferenças entre números e grandezas e assim pôde conceituar o funcionamento das operações fazendo analogias com o que seria inverso dos números dentro das operações de multiplicação e depois das outras operações. Historicamente, resolveu-se o problema conceitual, mas suscitou uma disputa por uma concepção epistemológica, não só sobre a existência dos números negativos, mas também sobre as operações com tais números.

As concepções epistemológicas sobre os números negativos, que iniciaram por volta da metade do 


\section{sala \\ de $\oplus$ em \\ aula foco}

REVISTA ELETRÔNICA

século XIX segundo nossas fontes históricas (SCHUBRING, 2012), por serem relativamente novas dentro da matemática enquanto ciência, parecem sugerir que existem alguns obstáculos importantes a serem transpostos para o seu ensino, mas, no entanto, deve ser considerada a questão sócio temporal. No nosso caso, didaticamente, concebemos que os "obstáculos de origem verdadeiramente epistemológica são aqueles dos quais não se pode e nem se deve fugir, por causa do papel formativo que assumem quando se busca um conhecimento" (BROUSSEAU, 1997, p.87; tradução nossa).

Para a sustentação teórica desse campo numérico, sabemos que muitas foram as contribuições dadas a fim de ultrapassar os supostos obstáculos epistemológicos apontados pela aceitação da existência dos resultados negativos como números. Estamos no final da segunda década do século XXI e vimos que muitas dessas contribuições fizeram uso de recursos didáticos, como as retas numéricas orientadas ou recorte de quadrados (SCHUBRING, 2012), por exemplo, para demonstrações e estipular regras em geral, que muitas vezes podem ser vistas como arbitrárias, mas com a finalidade de ultrapassar esse obstáculo sobre o entendimento dos números negativos e suas operações.

Mencionamos aqui os recursos didáticos, pois nos interessa refletir sobre uma experiência de ensino da operação de soma (e subtração) dos números negativos, em particular, inteiros, e não sobre o conceito de números negativos per se. Dessa forma, queremos incluir em nossa análise de investigação informações e reflexões que considerem o nosso recurso escolhido, que entendemos estar situado socialmente em nossas atuações docentes. Incluímos, como dimensão dessa investigação, um jogo confeccionado em um programa gratuito de computador chamado Scratch.

Desenvolvemos esse jogo como um recurso didático - demos o nome de Scratch no Deserto - para que, na nossa postura de investigação, tivéssemos um lugar bem definido de olhares sobre os supostos obstáculos epistemológicos, principalmente, os historicamente relatados até meados do século XIX e que justificam o ensino dos números negativos estar relegado tradicionalmente ao 70 ano do ensino fundamental - e ainda continuar assim na Base Nacional Comum Curricular (BNCC, 2017). Como outra dimensão de nossa reflexão de pesquisa, supomos esses obstáculos como uma estranheza que a apresentação e uso deliberado de números negativos e operações de soma com os mesmos poderiam causar em crianças nos anos iniciais do ensino fundamental do século XXI. 


\section{sala \\ de $\oplus$ em \\ aula foco}

REVISTA ELETRÔNICA

Para nós, o papel de um recurso didático nesta investigação deve ser encarado sob a ótica da transparência de Adler (2000), cujas funções de visibilidade e invisibilidade por ela propostas, fazem com que vejamos um recurso - tal qual um jogo de computador - como fonte de atenção e curiosidade no início de sua utilização, classificando-o como visível. No princípio, a atenção se volta a ele tanto pela curiosidade quanto pela dificuldade de entendê-lo e os estudantes tendem a focar no seu entendimento. À medida que o recurso é entendido e deixa de ser novidade, é possível aprender por meio dele, ou seja, ele passa a ser invisível/transparente e, no lugar de aprender com o recurso, aprende-se com ele. Esse olhar sobre os recursos baseia-se no fato de que
...a matemática escolar é uma prática híbrida - uma mistura da matemática cotidiana e acadêmica, e do aprendiz e das estratégias centradas no professor. Eu então uso o conceito de transparência e suas funções duplas de visibilidade e invisibilidade, a fim de examinar os recursos em uso na prática matemática escolar. Eu argumento que os conceitos prática híbrida e transparência de recursos fornecem ferramentas para a atenção bidimensional dos recursos e, consequentemente, para uma prática pedagógica mais dinâmica na sala de aula de matemática e na formação de professores de matemática. (ADLER, 2000, p.207; tradução nossa)

A própria BNCC (2017), ainda que tenhamos algumas críticas que não cabe aqui neste relato, traz considerações sobre a importância do uso de recursos no desenvolvimento de algumas competências específicas para o ensino de matemáticas, que gostaríamos de destacar, como na "competência específica 2: Desenvolver o raciocínio lógico, o espírito de investigação e a capacidade de produzir argumentos convincentes, recorrendo aos conhecimentos matemáticos para compreender e atuar no mundo" (BNCC, 2017, p.265).

Importa-nos também ressaltar que nossa postura investigativa acerca do ensino do conceito dos números negativos, do recurso que faríamos uso e como deveríamos considerá-lo - frutos da interação inerente à parceria entre os autores que ensinam matemáticas em etapas de escolaridade diferentes-, revela "como a investigação se relaciona à prática e o que os professores aprendem da investigação dentro das comunidades"2 (COCHRAN-SMITH, LYTLE, 1999, p.250) produz conhecimento. Pois, assumimos que

\footnotetext{
2 Tradução nossa.
} 


\section{sala \\ de $\oplus$ em \\ aula foco}

...o conhecimento ${ }^{3}$ que os professores precisam para ensinar bem é gerado quando os professores tratam suas próprias salas de aula e escolas como locais de investigação intencional ao mesmo tempo em que tratam o conhecimento e a teoria produzidos por outros como material gerador de interrogação e interpretação. (COCHRAN-SMITH, LYTLE, 1999, p.250 - TRADUÇÃO NOSSA)

Foi exatamente por meio de nossa interação, depois de debates e estudos coletivos realizados em encontros regulares e semanais, que idealizamos e programamos nosso jogo como um recurso que permitisse investigar intrinsecamente o ensino dos inteiros negativos, em suas ferramentas operatórias de soma, e, assim, apresentamos na próxima seção o seu funcionamento junto à nossa observação sobre sua aplicação piloto, concentrando nosso enfoque de análises no período que consideramos de 'transparência' (ADLER, 2000) do jogo.

\section{JOGO E A SUA APLICAÇÃO}

Como parte constituinte dessa investigação, precisamos descrever a criação de nosso recurso antes de situá-lo em nosso contexto de pesquisa. O Scratch é um programa concebido pelo Instituto Tecnológico de Massachussets (MIT) e pelo grupo KIDS da Universidade (pública) da Califórnia em Los Angeles (UCLA), que visa à criação de animações buscando a aprendizagem de programação de forma mais simples possível, por meio de blocos lógicos de programação prontos, no qual criamos o jogo Scratch no Deserto como apresentados na abaixo (FIGURA 3) ${ }^{4}$ :

\footnotetext{
${ }^{3}$ Essas autoras foram traduzidas para a Língua Portuguesa usando as palavras saber e o conhecimento com mesmo valor semântico. Neste caso, escolhemos a tradução de knowledge por conhecimento.

${ }^{4}$ No nosso caso, usamos a versão Scratch2, adquirida através do site: https://scratch.mit.edu/
} 


\section{sala \\ de \\ aula foco}

- REVISTA ELETRÔNICA —

Figura 3 - Layout da tela de programação do Scratch, com o nosso jogo sendo programado

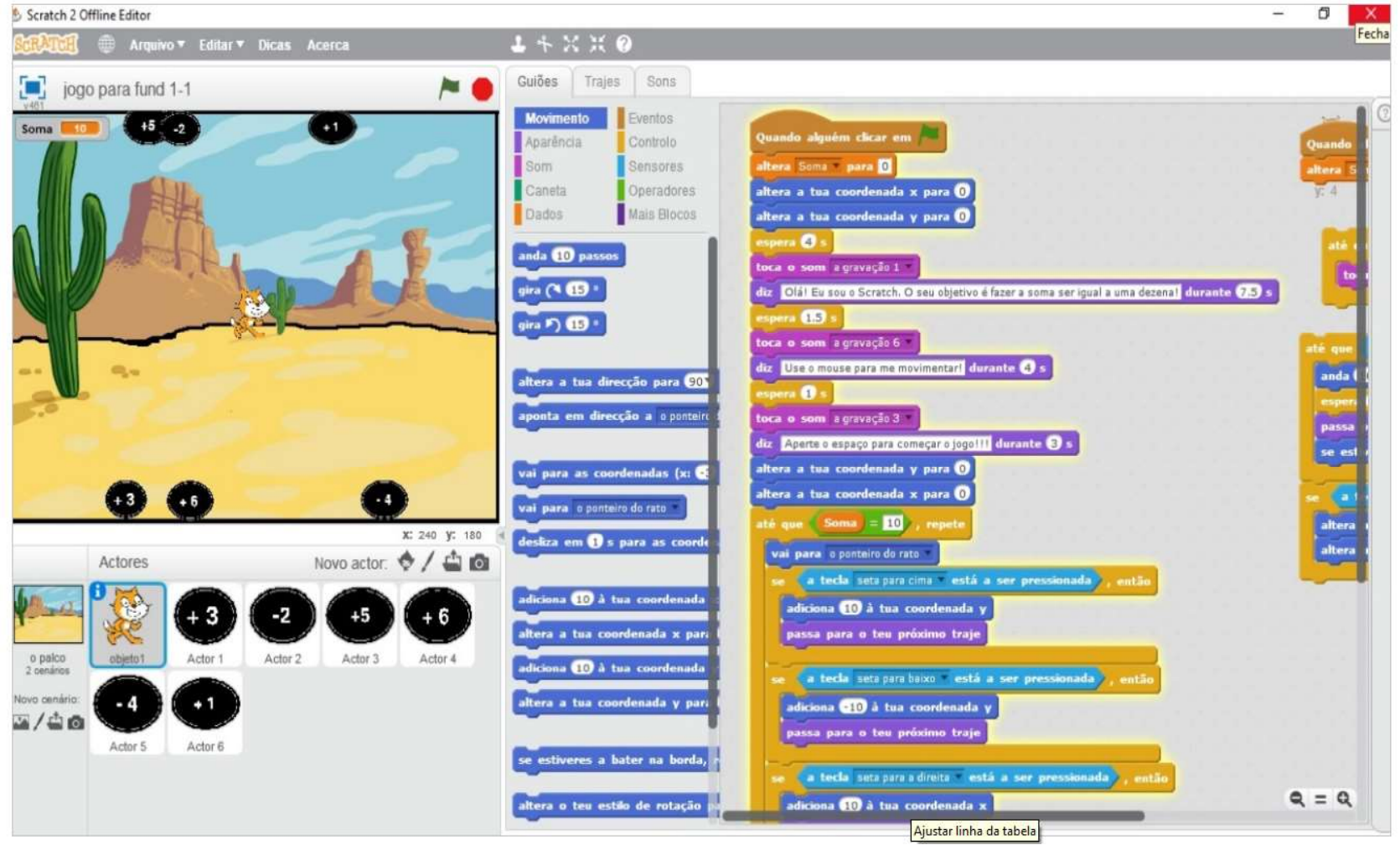

Fonte: os autores, 2018.

Não nos importa aqui descrever cada bloco lógico com comandos de movimento; aparência; som; caneta; dados; eventos; controle; sensores; operadores e demais blocos (de criação livre), mas destacar que subvertemos o destino inicial do programa para o qual aquelas instituições destinaram o Scratch, de ensinar crianças a programar, para criar um jogo específico que permitisse explorar o conceito de números inteiros positivos e negativos e a sua operação de soma. Pensamos num jogo digital para tal exploração por considerarmos que ensinar crianças do século XXI com este tipo de jogo nos parece motivador e significativo na/para a vida do estudante, que em primeira instância:

\footnotetext{
[...] Ihe possibilite um prazer em aprender, não pelo utilitarismo, mas pela investigação, ação e participação coletiva de um "todo" que constitui uma sociedade crítica e atuante, leva-nos a propor a inserção do jogo no ambiente educacional, de forma a conferir a esse ensino espaços lúdicos de aprendizagem. (GRANDO, 2000, p.15)
}

Aproveitando os recursos disponíveis, fizemos com que números inteiros positivos e negativos (+1, $-2,+3,-4,+5$ e +6$)$ se movimentassem pela tela de forma que o gato - que leva o nome do programa, Scratch-, guiado pelo mouse ou pelas setas do teclado do computador, toque nos números necessários 


\section{sala \\ de $\oplus$ em \\ aula foco}

REVISTA ELETRÔNICA

ISSN 2316-7297

para que a soma resulte em uma dezena positiva. Há uma narração junto a balões de fala orientando o que fazer no início do jogo, pensado para crianças que ainda tenham alguma dificuldade na leitura.

Essa etapa de criação também faz parte da nossa postura investigativa (COCHRAN-SMITH, LYTLE, 2009) que nos levou ainda a colocar como uma das dificuldades no jogo - como um possível obstáculo epistemológico (SCHUBRING, 2012) - o fato de que se o gato começar tocando em números negativos ou se, acidentalmente, durante o jogo, o gato fizer somas cujos resultados sejam negativos, o jogador precisaria (re)definir uma estratégia de escolha de números que o fizesse atingir o objetivo do jogo, a dezena positiva.

Escolhemos fazer uma aplicação piloto do jogo, individualmente, a dois estudantes do 20 ano do Ensino Fundamental - que à época da criação e aplicação, faziam parte das turmas de atuação das duas coautoras deste artigo - para que pudéssemos, a partir das observações, refinar e fazer ajustes no jogo, se fosse necessário, bem como estudar que tipo de mediação poderia ou deveria ser feita junto aos estudantes quando fosse feita a aplicação dele no coletivo de uma turma.

No primeiro contato com o novo jogo, ambos os alunos demonstraram uma certa inabilidade com o uso do mouse e o desconhecimento do nome da tecla espaço. Por isso, foi necessárias a mediação com muito cuidado, por meio do nosso exemplo mexendo o mouse e do nosso apontamento da tecla espaço, sanando tais inabilidades em um espaço de tempo bastante curto. Pudemos observar, entretanto, que o recurso tornava-se visível (ADLER, 2000), pois os estudantes estavam aprendendo sobre ele e não repararam tanto no que estava acontecendo no jogo. Algumas vezes, enquanto aperfeiçoavam o manejo do jogo, conseguiam atingir o objetivo, mas não relataram expressões produtivas de aprendizagem sobre o conteúdo intrínseco ao jogo e sim à novidade digital enquanto motivados a jogar como: "Legal isso!" e "Acho que minha turma vai gostar!".

Depois de nossos exemplos de como jogar, deixamos que jogassem livremente, pois Bezerra e Bandeira (2011) nos lembra que crianças e adultos pensam diferente e a atuação do professor como mediador não se resume a uma "colonizadora" forma de ensinar estudantes a jogar, mas de fazer o acompanhamento de como jogam e instruí-los a construir suas próprias estratégias para que possam entender o objetivo por trás de cada jogo. Nesse processo de liberdade para jogar, entendemos 


\section{sala \\ de $\oplus$ em \\ aula foco}

-REVISTA ELETRÔNICA

que o jogo começava a ficar invisível (ADLER, 2000) quando começamos a ouvir expressões como:

"Ah... quando fica negativo eu preciso colocar mais positivos para passar do zero". Ou seja, estavam começando a aprender com o recurso. Inclusive, nessa última fala, nos indicaram seu olhar para o zero não como quantidade, mas como uma posição a ser ultrapassada.

Dessa forma, após entenderem que o gato precisava pegar os números que fariam a soma ser uma dezena (positiva), o fizeram sem demonstrar o menor estranhamento da existência dos números negativos. Mesmo quando apresentaram deslizes e dificuldades motoras próprias do jogo e fizeram a soma parcial ser negativa, a reação deles passou a, simplesmente, dizer: "Preciso procurar os positivos". Dessa forma, além de percebermos cada vez mais a familiaridade com o recurso, inferimos que o obstáculo epistemológico (SCHUBRING, 2012) causado pela aparição dos inteiros negativos e a operação de soma com eles foi facilmente vencido, considerando as falas das crianças trazidas até aqui. Na verdade, não percebemos nem olhares nem expressões dos alunos que denotassem alguma estranheza ao verem e operarem com os números inteiros negativos.

Ao contrário, as crianças nos mostraram até um certo conforto em arrumar estratégias e até externálas para nós quando perceberam que, ao juntarem negativos, o resultado parcial ficava cada vez mais negativo, de acordo com as seguintes falas: "Ih...encostei no -2 e no -4, agora vou ter que encostar no +6 para voltar pro zero" e "Fiz um teste agora aqui e vi que se eu tocar no -4 duas vezes e depois no -2 ele fica -10, legal! Mas agora eu tenho que somar +20 então...ih...vai demorar mais, putz!". Inferimos que eles demonstraram estarem aprendendo com o nosso jogo/recurso e produzindo estratégias pessoais para resolverem seus problemas.

Segue abaixo uma tela com uma sequência de etapas do jogo em uma aplicação (FIGURAS 4 e 5).

Revista Eletrônica Sala de Aula em Foco, ISSN 2316-7297 - Volume 09, Número 01, 38-51, 2020 


\section{sala \\ de $\oplus$ em \\ aula foco}

- REVISTA ELETRÔNICA

Figura 4 - Telas do progresso do jogo em uma das aplicações (I)

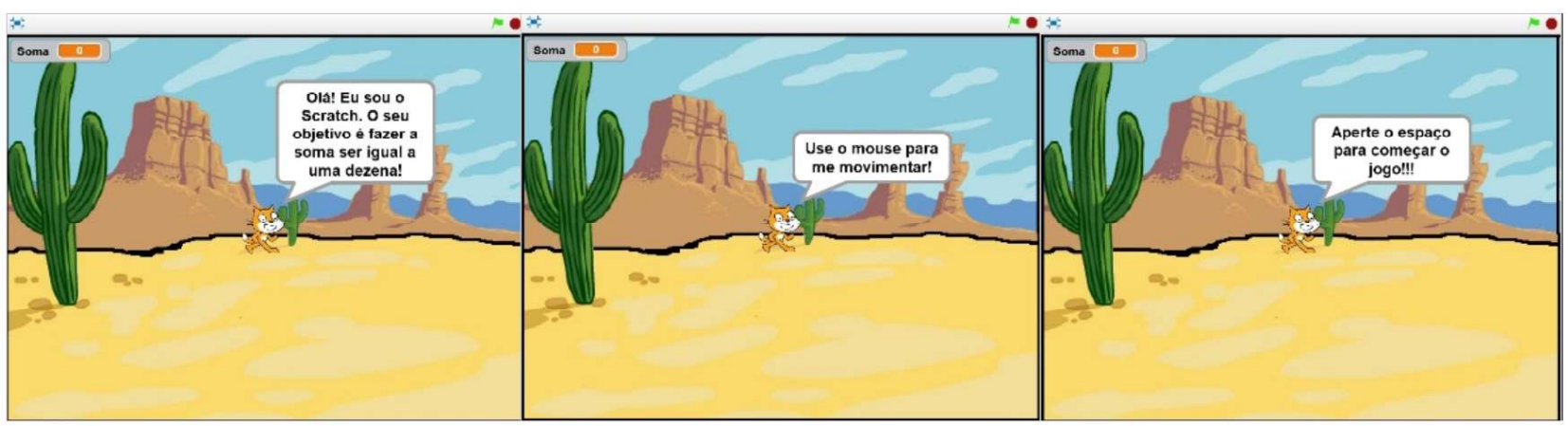

Fonte: nossa, 2018

Figura 5 - Telas do progresso do jogo em uma das aplicações (II)

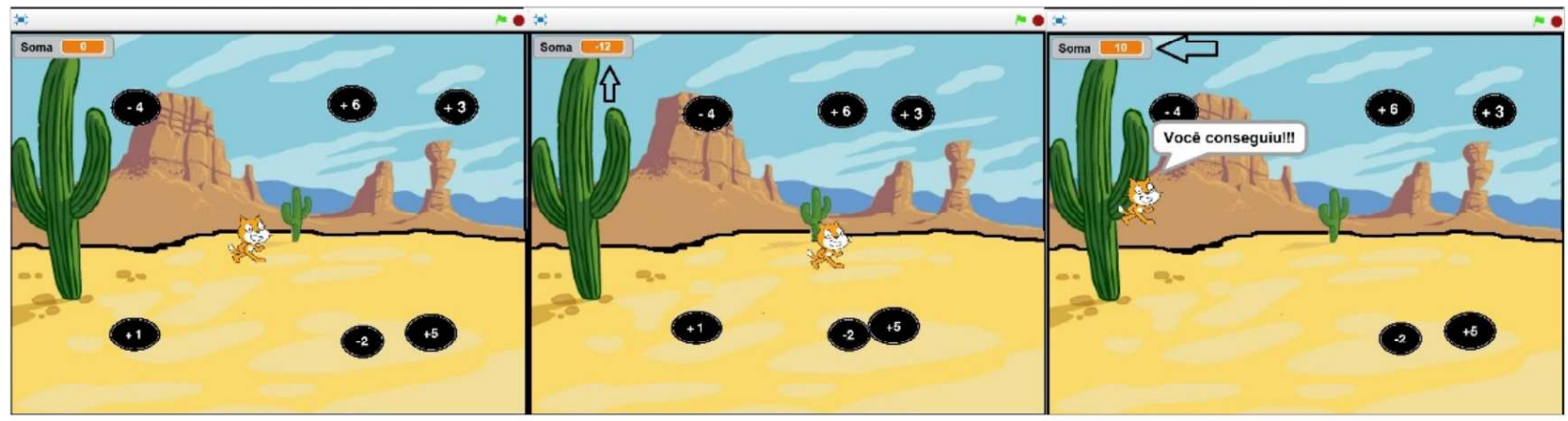

Fonte: os autores, 2018.

Ao final das aplicações do jogo, recolhemos nossas anotações e, além das análises das situações observadas e aqui comunicadas, as usamos como registro para futuras ações pedagógicas e deixamos nossas considerações acerca dessa atividade de investigação no contexto de nossas próprias práticas (COCHRAN-SMITH, LYTLE, 1999) sobre o ensino dos números inteiros negativos já nos anos iniciais de escolarização.

\section{CONSIDERAÇÕES}

Consideramos que a parceria inicial entre professores que ensinam matemáticas e atuam em diferentes etapas de escolarização criou um ambiente favorável para construirmos uma investigação enquanto postura docente (COCHRAN-SMITH, LYTLE, 2009) acerca do ensino das operações de soma com números inteiros. Atuamos como uma espécie de mini comunidade investigativa, que tomou por hipótese o fato de que crianças do século XXI tem gosto por jogos digitais e já são familiarizadas com os números negativos por meio desses jogos, mas também por outras situações cotidianas, como o 


\section{sala \\ de $\oplus$ em \\ aula foco}

-REVISTA ELETRÔNICA

saldo de gols de um time dentro de um campeonato de futebol - extremamente popular -, saldos bancários e econômicos, em geral divulgados pelas grandes mídias como a televisão, e informações sobre lugares muito frios, que nevam ou tem geleiras e têm temperaturas negativas.

Em nossa investigação usamos um jogo digital, produzido no programa Scratch, que serviu como recurso didático para o ensino da soma de números inteiros positivos e negativos, ao mesmo tempo em que ajudava a produzir dados advindos das reações das crianças ao usá-lo. Consideramos que entender o processo de transparência (invisibilidade) deste jogo - a partir do qual Adler (2000) admite que se está aprendendo através de um recurso -, permitiu-nos perceber que os números negativos não causaram praticamente estranheza alguma às crianças e nem as operações de soma entre os negativos e positivos.

A hipótese de termos que ultrapassar um possível obstáculo epistemológico (SCHUBRING, 2012) causado pelos números negativos com alguma facilidade, pode estar atrelada à abordagem adotada. Usando como o recurso didático um jogo, criado com ferramentas socialmente situadas como as computacionais, não nos pareceu ser tão difícil, visto a naturalidade com que as crianças discutiram as possibilidades de "passar do zero" (para cima ou para baixo) sem estranheza alguma. Isso nos leva a crer, ainda, que essa abordagem de apresentação abre novas possibilidades de mediação sobre o ensino dos negativos, que pode ser aproveitada, inclusive, junto a estudantes de anos mais adiantados.

Mas, reconhecendo a dependência das ações e postura docentes, não consideramos necessário esperar até o 7ํano, como previsto nos currículos, para começar a ensinar sobre os números negativos. É preciso estudo e planejamento - de preferência, num coletivo - da maneira que deve ser feita, considerando cada contexto está situado no tempo e lugar, como nosso jogo foi pensado. Por esses motivos, recomendamos um olhar mais cuidadoso e crítico para a Base Nacional Comum Curricular (BNCC, 2017) brasileira questionando, dentre outras coisas, o porquê do paradigma dos números positivos, mesmo racionais, perdurarem até o 70 ano de escolaridade. Parece existir um persistente senso comum de que operar e conceber os negativos como números foi e continua sendo algo estranho ao cotidiano do ser humano e da própria matemática, como aparentava ser até o século XIX. 


\section{sala \\ de $\oplus$ em \\ aula foco}

REVISTA ELETRÔNICA

Infelizmente, não houve tempo hábil para uma aplicação coletiva deste nosso jogo que pudesse ser comunicada ainda neste artigo, por questões de limitação de tempo institucional da escola onde fizemos a investigação, mas sabemos que ela ocorreu no ano seguinte. Deixamos, porém, o ensejo em realizar mais ações investigativas, principalmente em um ambiente essencialmente colaborativo entre pares que ensinam matemáticas, tendo como objeto de pesquisa a sala de aula e a própria prática em ensinar os conceitos matemáticos. Deixamos com essa experiência de parceira e investigação sobre os inteiros positivos e negativos uma primeira reflexão que possa contribuir tanto no modo de ensino do conceito de números negativos, quanto numa mudança de paradigma curricular que entenda a possibilidade de incluí-lo já nos anos iniciais do Ensino Fundamental.

\section{REFERÊNCIAS}

ADLER, J. Conceptualising resources as a theme for teacher education. Kluwer Academic Publishers. Journal of Mathematics Teacher Education 3: 205-224, 2000.

BEZERRA, S. M. C. B.; BANDEIRA, S. M. C. Metodologias alternativas no ensino da matemática: jogos e oficinas pedagógicas. Revista Ramal de Ideias. Rio Branco, v. 1, n. 1, p. 1-16, 2008. Disponível em: $<$ http://www.ufac.br/portal/unidades-administrativas/orgaos-complementares/edufac/revistaseletronicas/revista-ramal-de-ideias/edicoes/edicao-1/caminhos-dos-numeros/metodologiasalternativas-no-ensino-da-matematica>. Acesso em: 19 abril de 2019.

BRASIL. Base Nacional Curricular Comum. Brasília: MEC, 2017. BRASIL. Instituto Nacional de Estudos e Pesquisas Educacionais Anísio Teixeira (INEP).

BROUSSEAU, G. Theory of didactical situations in mathmatics: didatique des mathématiques, 1970-1990; ed. e traduzido por Nicolas Balacheff, Dordrecht: Kluwer Academic Publ. 1997.

COCHRAN-SMITH, M.; LYTLE, S. L. Relationships of knowledge and practice: teacher learning in communities. Review of Research in Education, 1999, 24, p.249-305.

\section{Inquiry as stance: Practitioner research for the}

next generation. Capítulo 5. New York: Teachers College Press. Traduzido por: Maria Amélia A. Nader; Maristela M. Kondo Claus, 2009.

GRANDO, R.C. O Conhecimento Matemático e o Uso de Jogos na Sala de Aula. 2000. 239f. Tese (Doutorado), Universidade Estadual de Campinas, Campinas, 2000.

LAVE, J. Situating learning in communities of practice, chapter 4. Em L. Resnick, J. Levine, e S. Teasley (Eds.), Perspectivas sobre a cognição socialmente compartilhado (páginas 63-82). Washington, DC: APA, 1991. 


\section{sala \\ de $\oplus$ em \\ aula foco}

SCRATCH em Língua portuguesa: <https://scratch.mit.edu/>. Acessado em 20 de janeiro de 2016.

SCHUBRING, G. Os números negativos: exemplos de obstáculos epistemológicos? Rio de Janeiro.

E-LIMC, 2012. 